\title{
الرؤية المعاصرة في التصميم الداخلي للمتحف السعودي
}

إعداد

سلافا بنت محمد برن عبد|لرحمـ دماود

كلية الفنون والتصميم الداخلي بمكة المكرمة

قسم السكن وإدارة المنزل - جامعة أم القرى

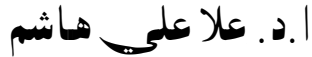

كلية الفنون والتصميم الداخلي بهكة المكرمة

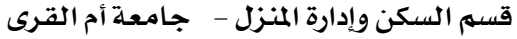

مجلة بحوث التربية النوعية ـ جامعة المنصورة

علد (rTr 


\section{الروئية المعاصرة في التصميم الداخلي للمتحف السعودي}

إعداد

$$
\text { سالافا بنت محمد بزعبد الرحمزداود* }
$$

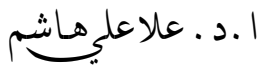

الاقدهمة:

لقد أخذ الاهتمام بإنشاء المتاحف ورعايتها يتزايد يوماً بعد يوم حتى أخذات مكانـة مرموقة

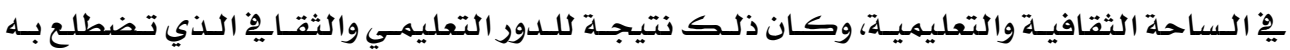
المتاحف كوسيلة اتصال تعليميلة تهيىءعن طريقها الخبر ات التعليمية الواقعية المباشرة.

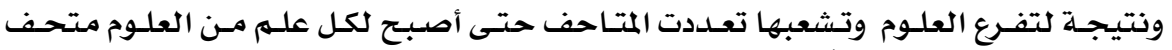

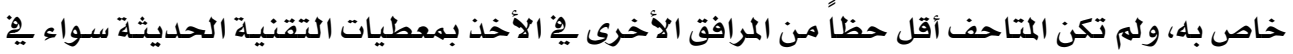

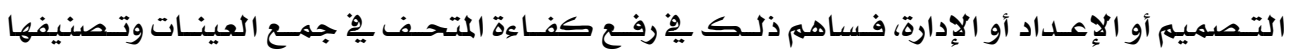

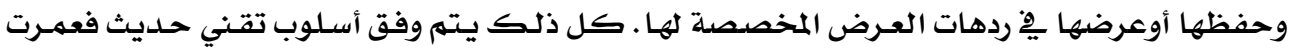

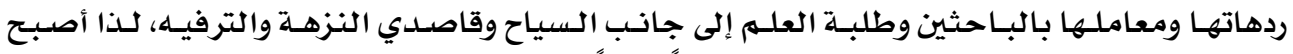

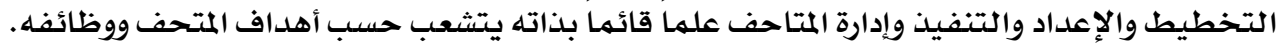

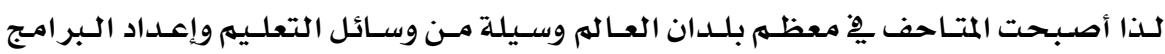

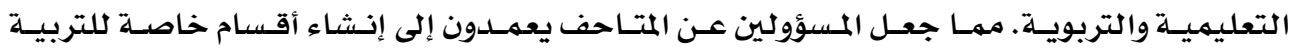

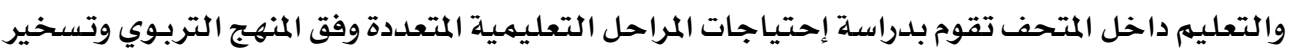

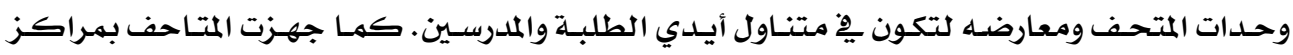

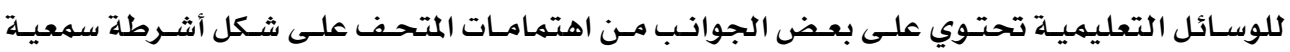

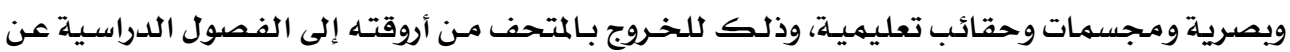

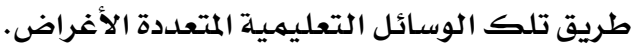

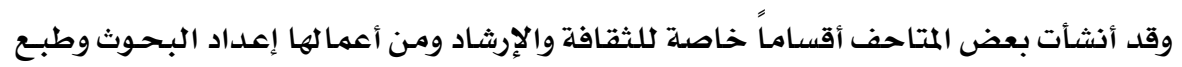

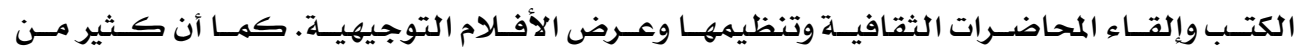

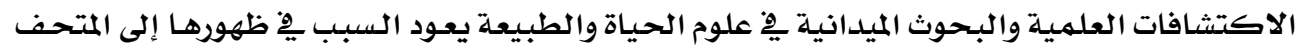

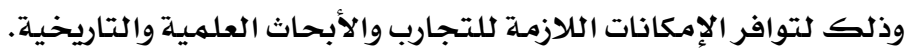
وإلى جانب ماسبق، علينا أن لانغفل أهم الأدوار التي يلعبها المتحف يِّ تعريف جمهـور النزوار

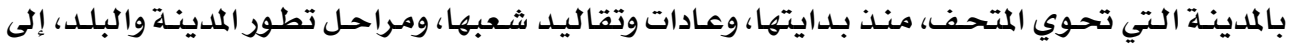

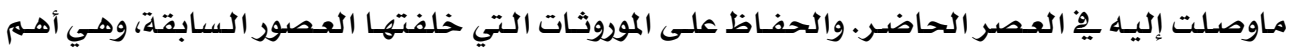
شواهد على تلك الحضارات.

* كلية الفنون والتصميم الداخلي بمكة المكرمة - قسم السكن وإدارة المنزل - جامعة أم القرى 


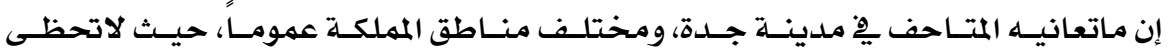

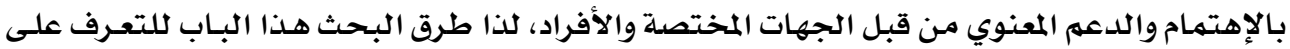

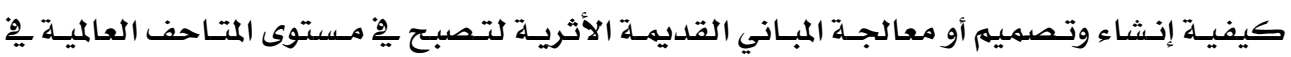

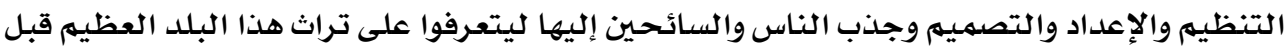

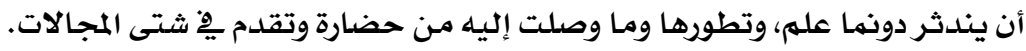

\section{أهد|ف البحث:}

ا ـ التعرف على أفضل الطرق التصميمية لمعالجة الفراغ الداخلي للمتحف.

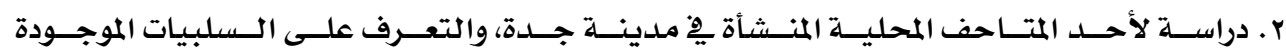
ومعالجتهاعلى أسس علمية تصميمية صحيحة. لونة

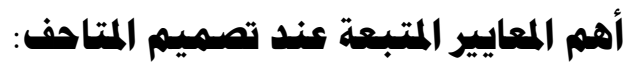
ا - إختيـار المهوقهـع :

إن إختيار موقع المتحف يعد من أهم العوامل التي تتدخل يِّ نجاح جذب الجمهور والعامـة له وهناك شروط عامـة يستلزم توافرها يِّ الموقع وهي :

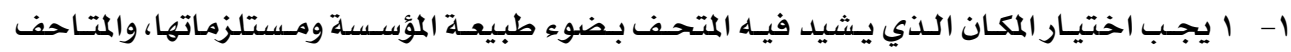

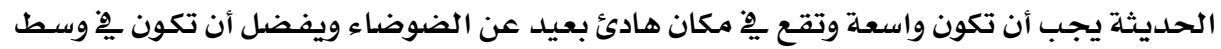

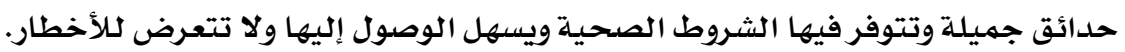

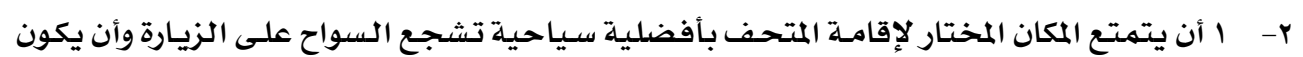

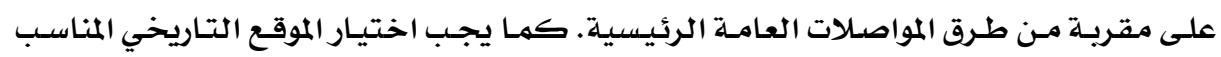

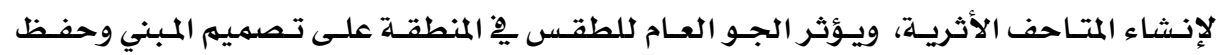

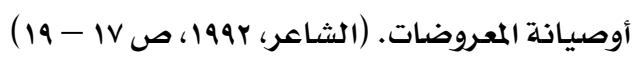

r- ا أن تتناسب مساحة الموقع مـع عدد الأجنحة والجمهور المتوقع لتلايِ التكدس.

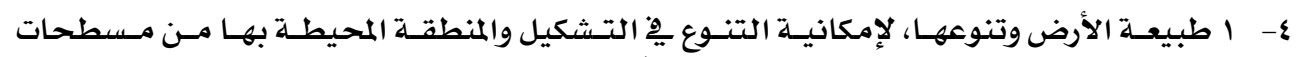

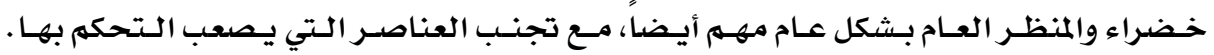

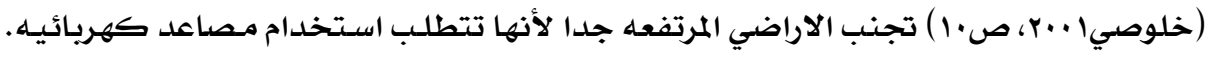

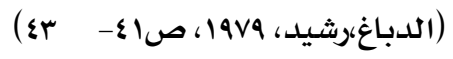




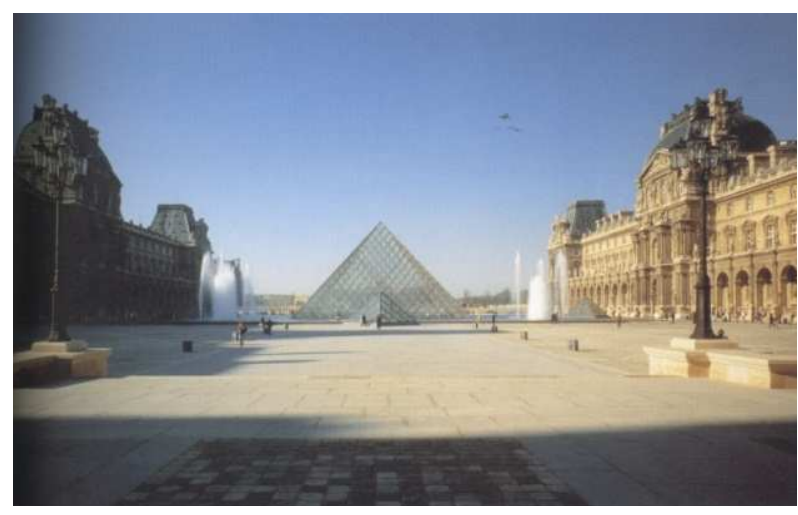

صورة (1) توضح متحف اللوفر من الخارج

:

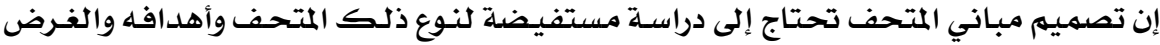

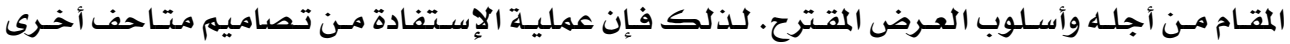

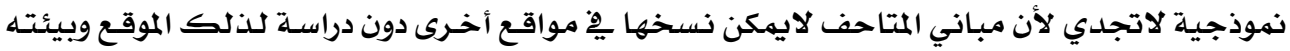

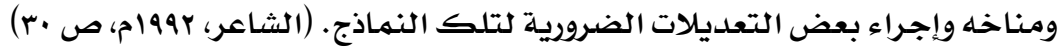

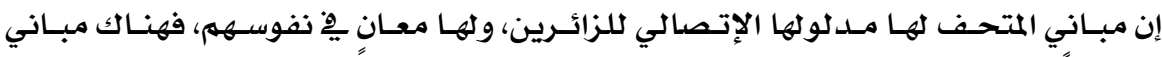

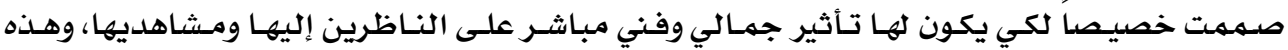

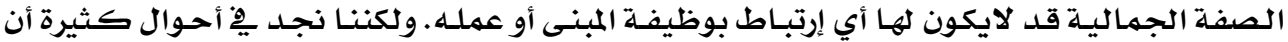

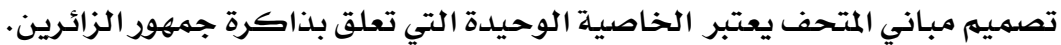

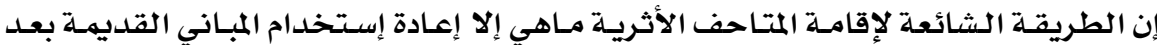
تعديلها وجعلها مناسبة له. وخير دليل على ذلك متحف اللوفر ِِّ فرنسا، وهيرميتاج، وبرادو وغيرهـا

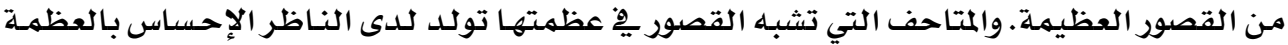

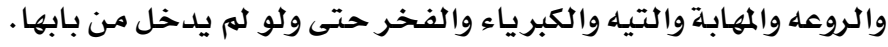
ب-توزيع المساحات داخل المتحف :

هناك ثلاث مساحات رئيسية يشغلها المتحف وهي :

$$
\begin{aligned}
& \text { • منطقة عامـة خاصدة بالجمهور } \\
& \text { • مساحات خاصدة بالمكاتب والإدارة }
\end{aligned}
$$

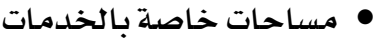

1 - المساحات الخاصلة بالجمهوروتقوم بالوظائف الآتية :

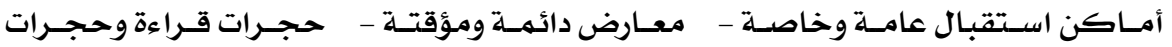

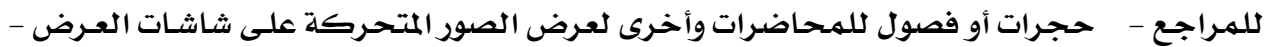


حجـرات للإجـتهـاعـات و الإسـتراحـات - مقهـى أو مطعهم، ومتجـر مبيعـات، وأمـاكن للـورث الخاصسة

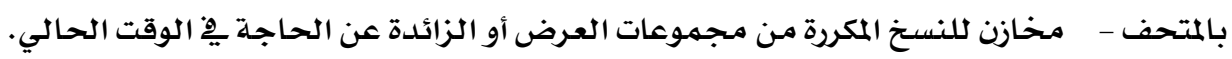
r - المساحات الخاصدة بالمكاتب والإدارة: تغطي الوظائف التالية الإدارة، الصيانة والترميهم والتسسجيل والتوثيق. با - مسساحات خاصدة بالخدمات:

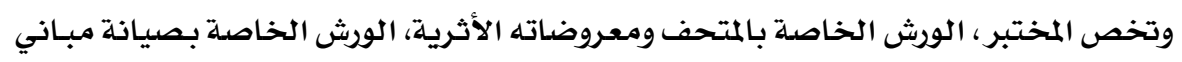

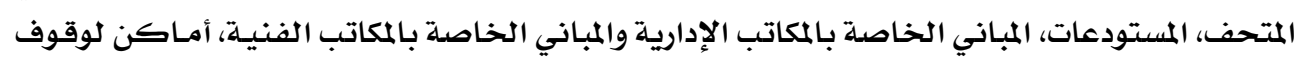

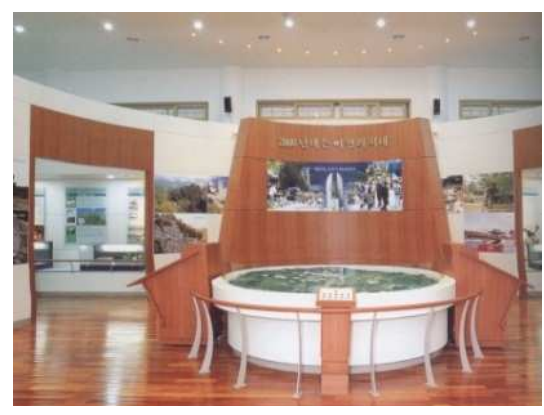

صورة رقم (r) الردهة ِِِ المدخل
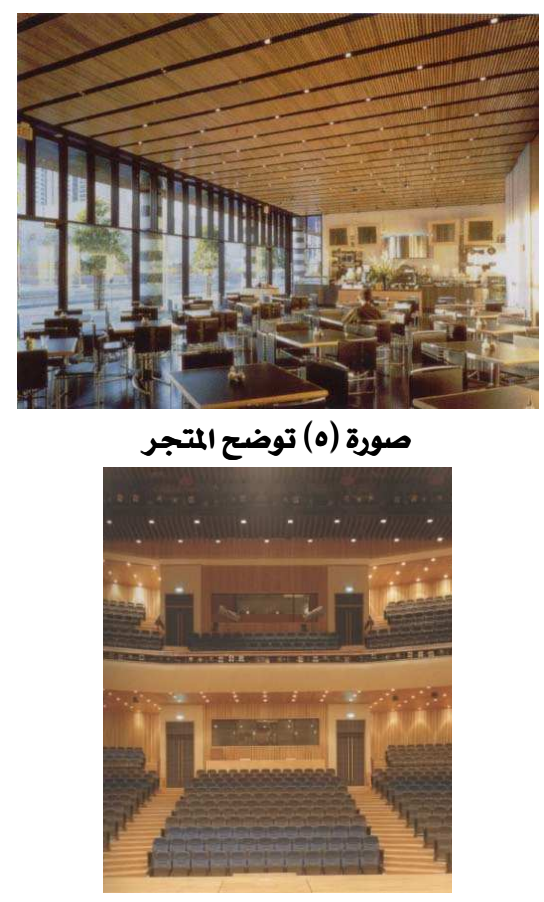

صورة (v) قاعة المؤتمرات

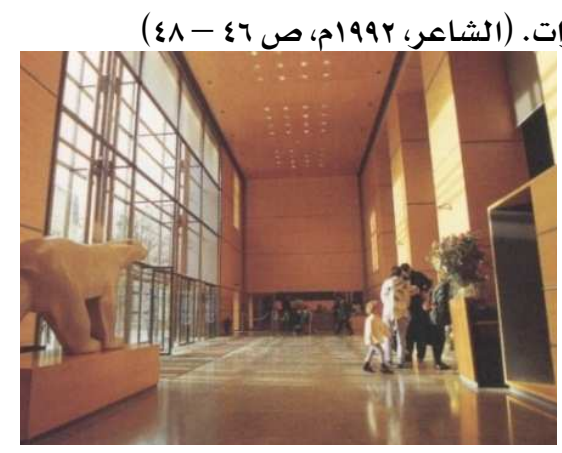

صورة (r) مكتب الاستقبال
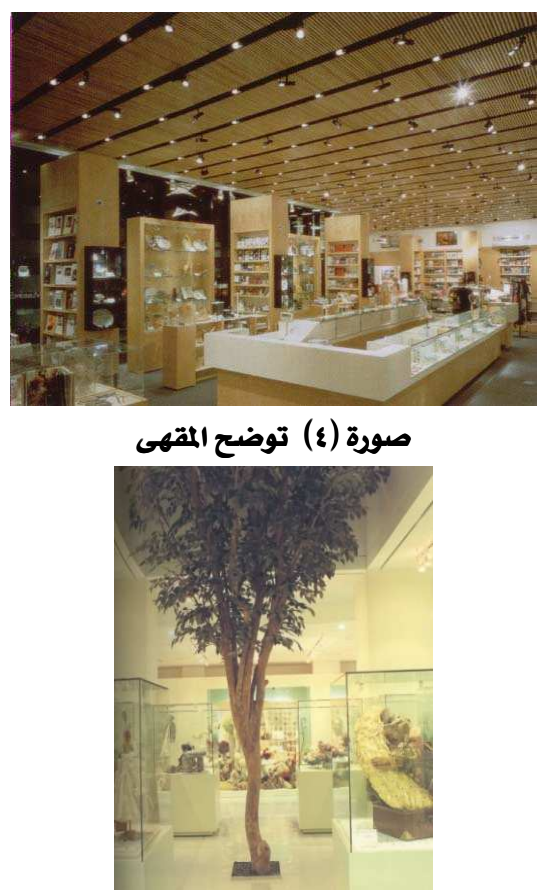
صورة (7) كيفية استخدام النبات داخل قاعة العرض 
ع - الممرات داخل المتحف:

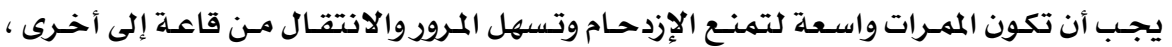

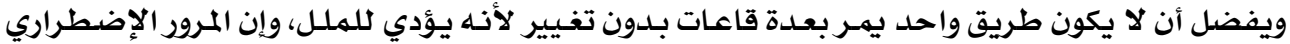
عبر عدد قليل من القاعات لا اعتراض علئ عليه.

وتظهـر مسشاكل المـرور فِّ صـوبة التوفيـق بـين العـرض لغالبيـة المشاهدين الـذين يـزورون

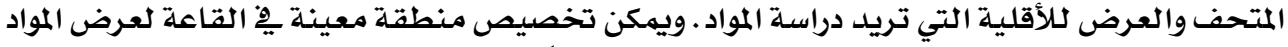

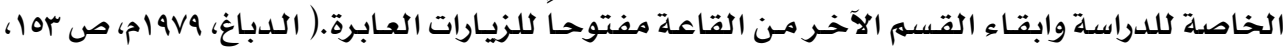

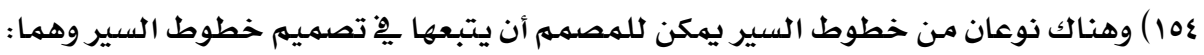

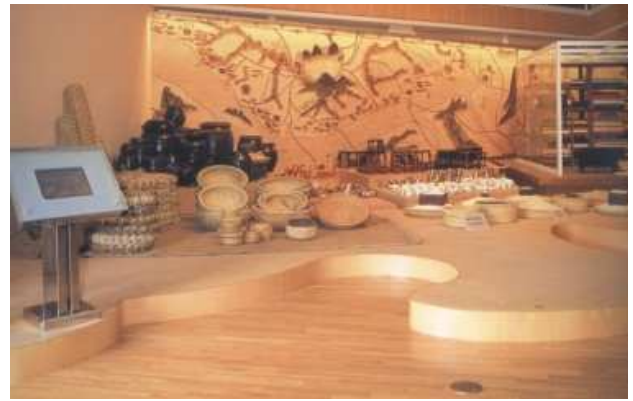

- 1 - خط سير محدد

ويسستخدم إذا كـان هـدف المعـرض

تقديم موضوع متسلسل ويتحتمم معسه أن يرىى كل شخص كل شيء.

صورة (^) خط السير المحدد

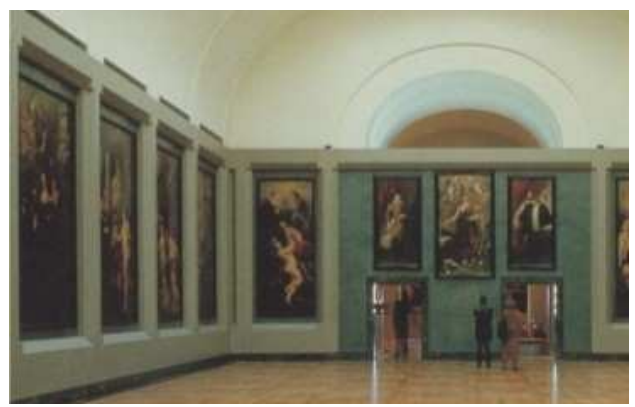

r- خط سير حر

يتبـع ٍِِ المعارض انتي لاتحتـاج إلى

التسلسل، بحيث يترك للزائر فرصة التجول.

صورة (4) خط السير الحر

وهناك ثلاثة مبادئ للعرض الجيد وهي :

ا . عـلـم تكـديس صـناديق العـرض بـالمعروضـات، لأن ذلـك يفقــ العينـات قيمتهـا العلميـة والجماليـة وبالتالي اهتمهام الزائرين.

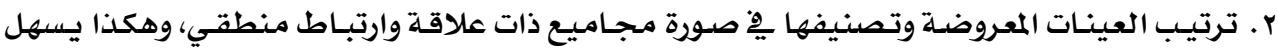
على الزائر تتبع فكرة العرض واستيعابها . r. تقسيهم فكرة العرض إلى وحدات صغيرة بحيث يحوي كل صندوق عرض فكرة مستقلة. 
ا ـ أن يتوفر به شروط الأمن والسـلامهة. r. ب أن تتوفر فيه الرؤية الواضحة. r. أن يثير الإهتمام ويجذب الانتباه.

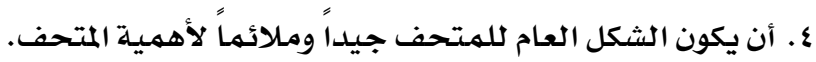

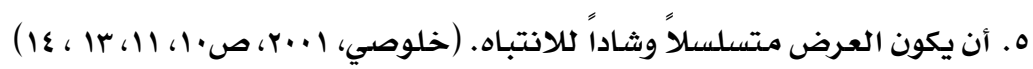

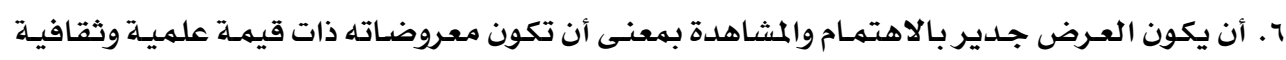
تهمى عامة الزوار.

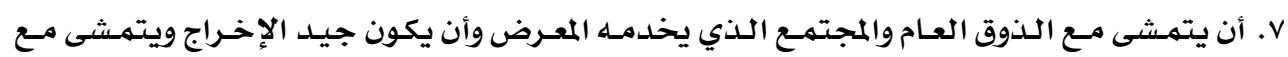

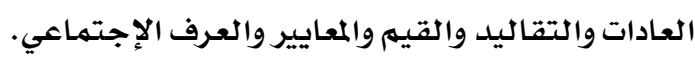

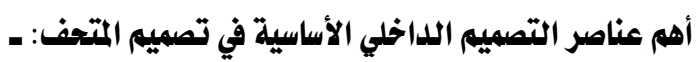
- 1- n

يجب أن تكون فتحات الأبواب بسيطة خالية من الزخرفة المعمارية، وتعتمد سعتها على حجم الماري

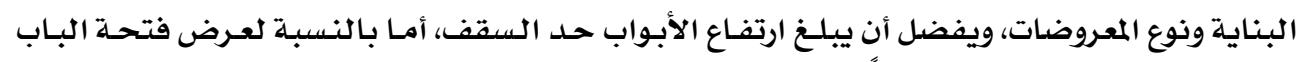

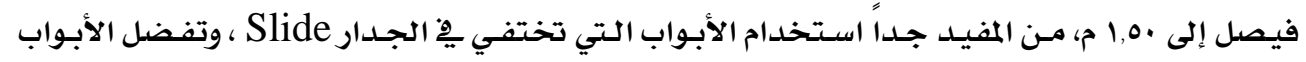

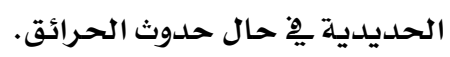

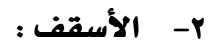

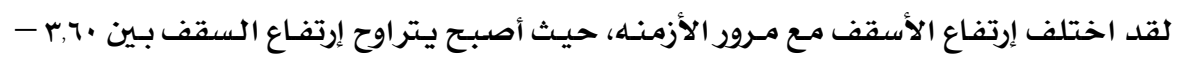

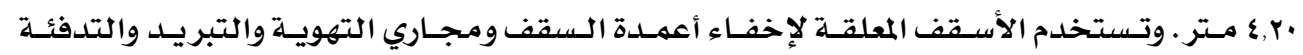

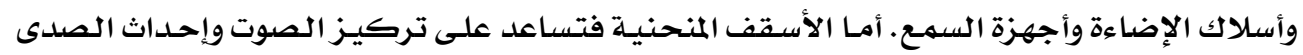

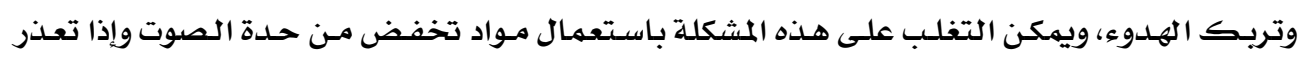

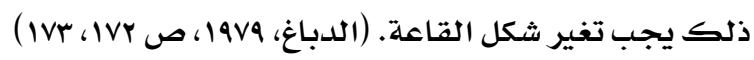

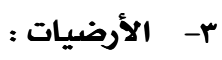

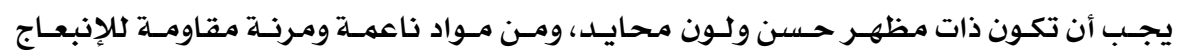

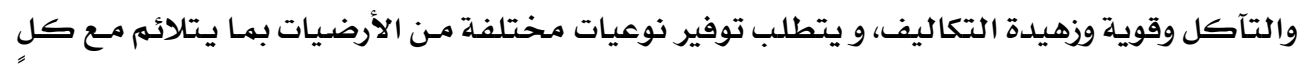

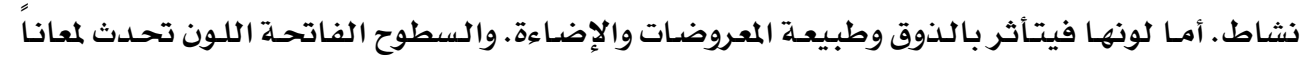

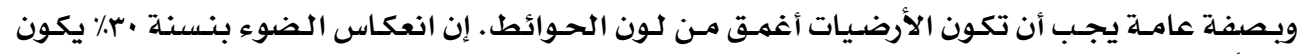

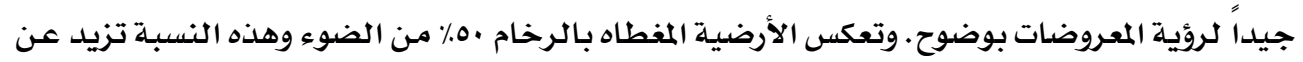

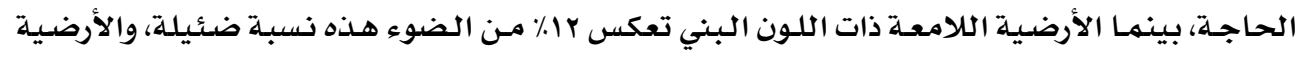

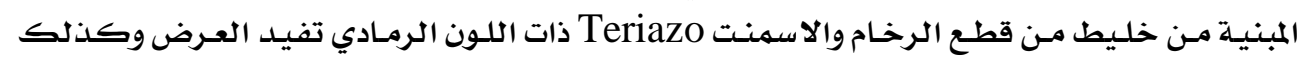




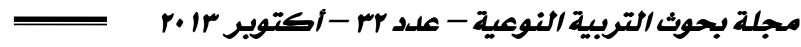

الخشب يؤدي نفس النتيجـة. ويجب تجنب الأرضسيات المزخرفـة والمزينـة بـالنقوش لأنها تلفت انتبـاه

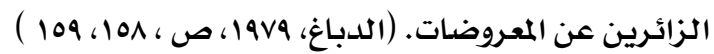

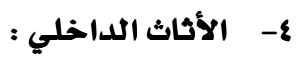

\section{ويتضمن الأثاث الداخلي البنود التالية:}

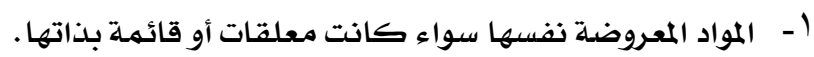

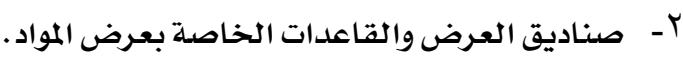

؟ ا- بطاقات التعريف بالقطع المعروضية.

ـ - أجهزة سمعيلة وبصرية.

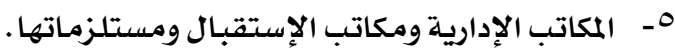

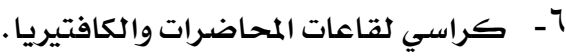

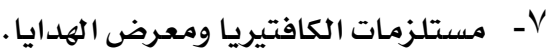

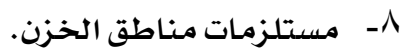
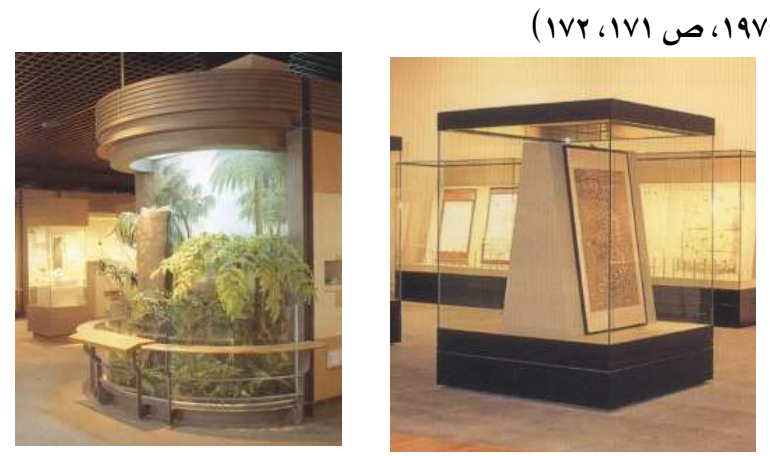

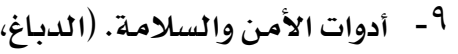

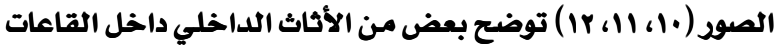

أهم عناصر التصميه اللداخلي المؤثرة في تصميي المتحف: ـ

ا- إضاءة المتحف:

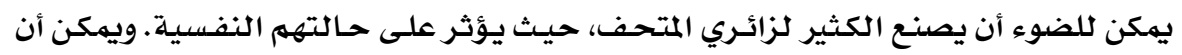

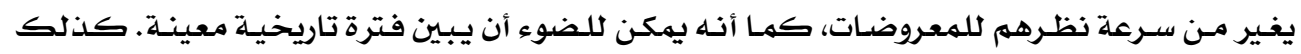

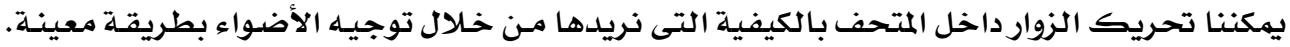

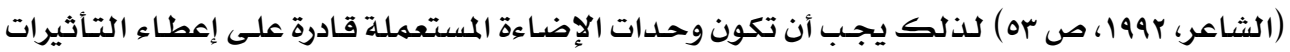

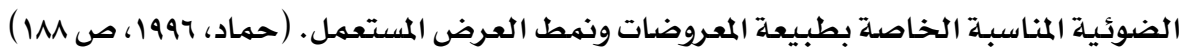


ويمكن أن نستخدم نوعـان مـن الأضـواء : الأضـواء الزاهيـة، والأضـواءالمتوهجة ـ ـ إن مصابيح

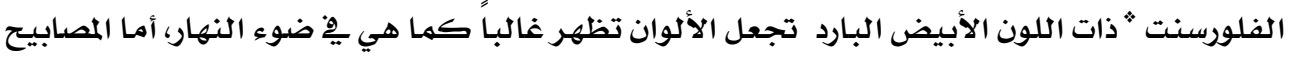

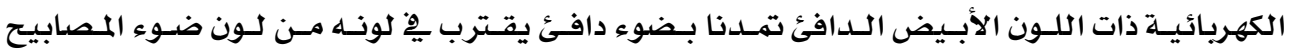

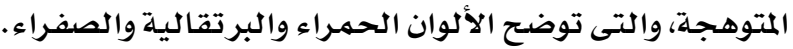

يوضـح جدول رقم (1) بعض التغيرات اللونية التى تحدث نتيجـة لاستعمال الانواع المختلفـة من المصابيح الكهربائية.

(1) (1) (1) (1)

\begin{tabular}{|c|c|c|c|c|c|}
\hline \multicolumn{4}{|c|}{ التفيرات اللونية الحادثة } & \multirow{2}{*}{ اللوز الملدهون به } & \multirow{2}{*}{ مسلسل } \\
\hline أبيض دافئ فاخر & أبيض بارد فاخر & أبيض بارد قياسي & متــوهــج & & \\
\hline اصفر غامق شديلد & اصفر زاه & اصفر زاه & برتقالي مصفر زاه & اصفر خفيف & 1 \\
\hline ازرق ارجواني & ازازرق محمر & اززرق رمادي & اخضر مزرق & ازرق متوسط الزرقة & $r$ \\
\hline احمر برتقالي & احمر كرزي (فاتح) & احمر مصفر & احمر برتقالي زاه & احمر فاتح (كرزي) & $r$ \\
\hline
\end{tabular}

وعند استخدام مصابيح الفلورسنت يجب أن تكون على بعـد ( . r.r) م على الأقل مـن السطح

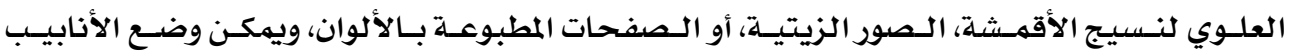

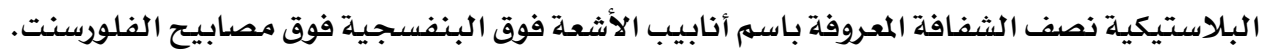

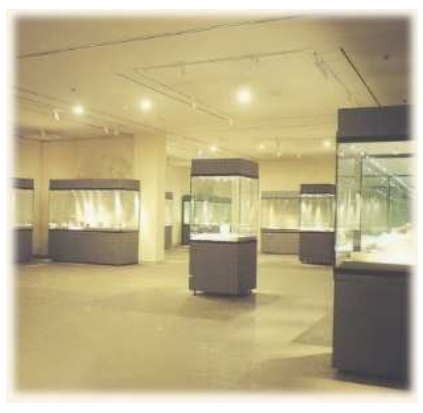

الصورة (rا ) اضاءة الخزانات

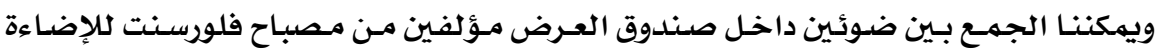

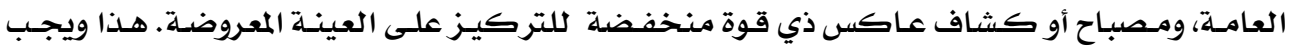

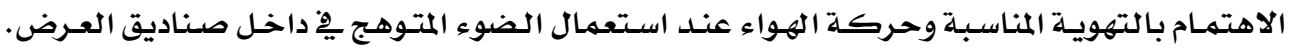

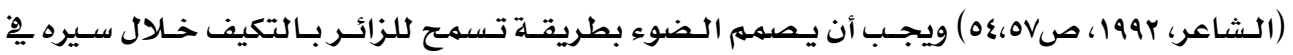

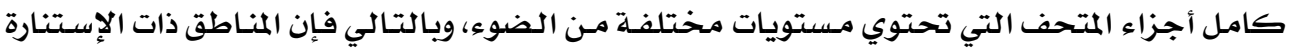

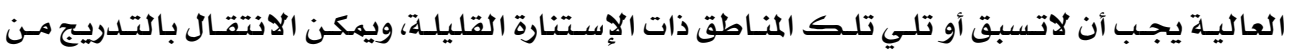

" الفلورسنت هي عبارة عن أنبوب من الزجاج المدهون ببـودرة الفلورسـت والمملؤ ببـخـار الزئبـق والآرجـون، وعند مـرور التيـار الكهريائي تشع الغازات اشعاعات فوق بنفسجية تؤثر على الفلورسنت والذي بـدوره يعطي الضوء المنظور. وتوفر لنـا هـذه 
مناطق مضاءة إضـاءة عالية إلى الأقل فالأقل، بحيث تتكيف العـين بالتدريـج على المستويات المختلفـة.

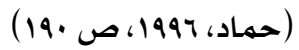
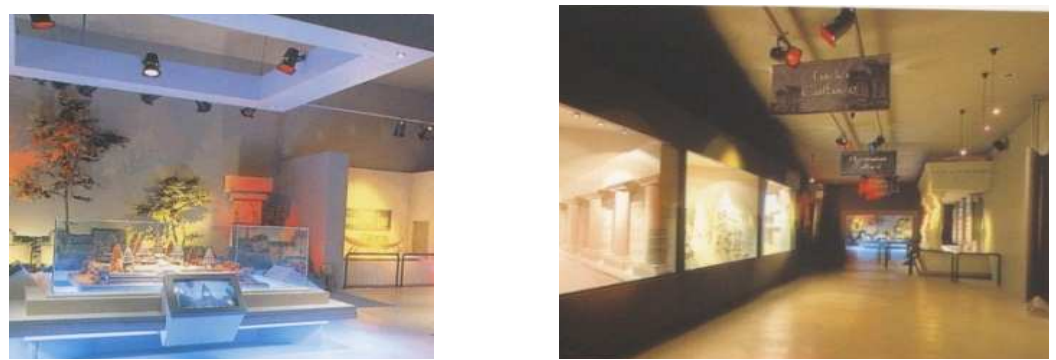

الصورتين (ع)، 10) توضحان تأثير الإضاءة على المعروضات

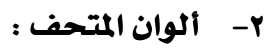

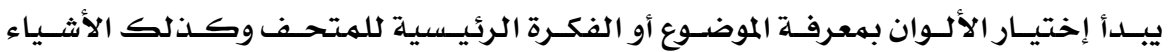

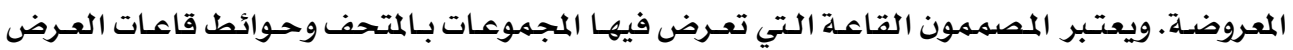

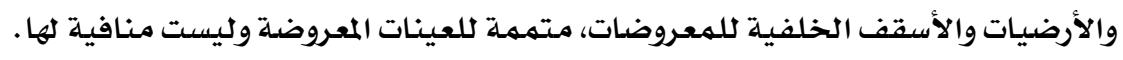

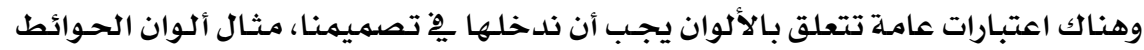

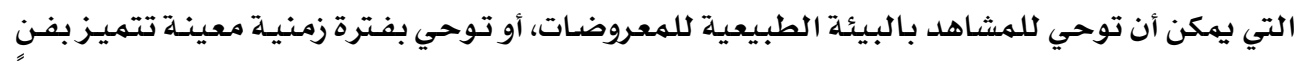

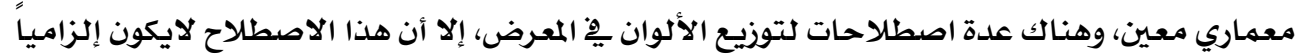

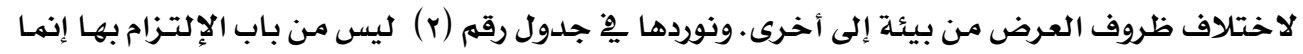

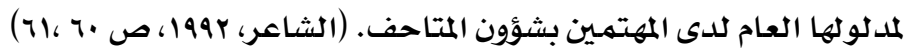
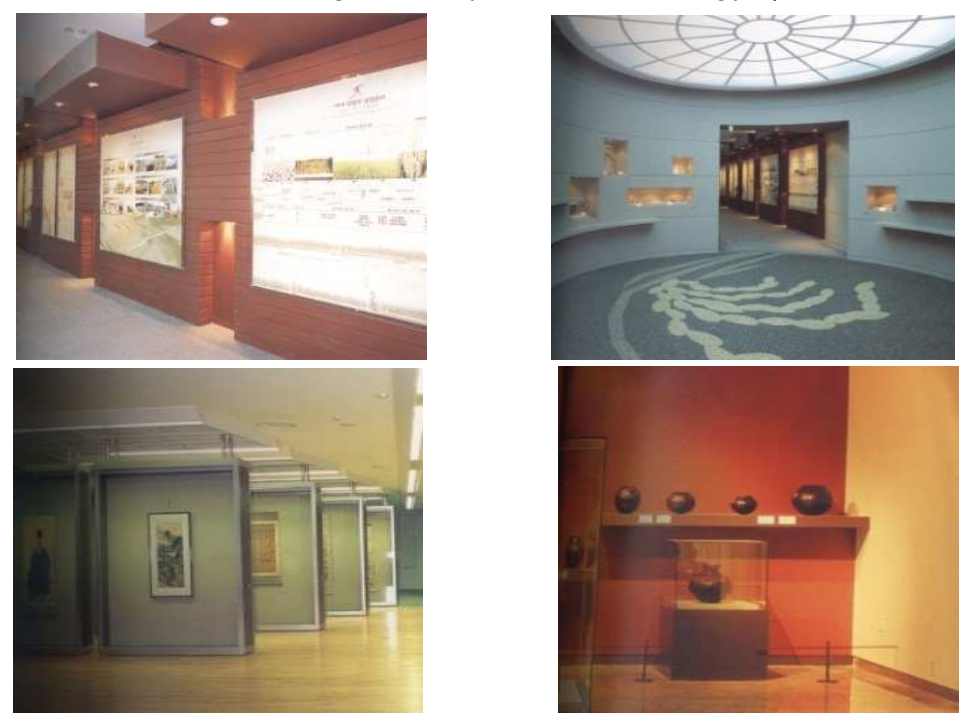

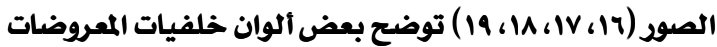




\begin{tabular}{|c|c|}
\hline مــدــــــــــــــــــ & الــــــــــــــون \\
\hline بالمتاحف التاريخية. يستعل الخشب في معـارض التعـلـين الخاصـة باستخراج المعـادن مـن المنــاجم الموجــودة & 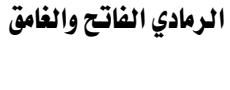 \\
\hline يستعمل في حالة الآلات أوالكنات الزراعية والمصانع وماكينات البخار. & الأحسمــــر \\
\hline يستعمل في حالة عرض الصناعات اليدوية التي تثثل التراث الشعبي، وعند عرض الطيور. & 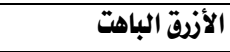 \\
\hline يستخدم في حالة عرض الصناعة أو منتجات تلك الصناعة. وأيضاً عينات الحيوانات البرية. & الأصفر الزاهي \\
\hline 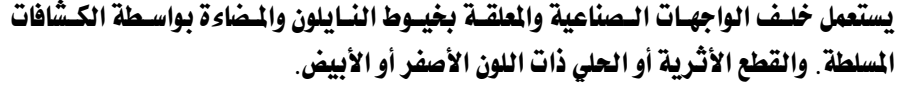 & الأخضر الفامق جلداً \\
\hline والمحيطات. يستعل حالة عرض الآثار الخاصة بحضارات البحـر المتوسط، أو عينـات حيوانـات البحسار & 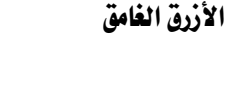 \\
\hline يستعمل هو والأبيض والرمادي عند عرض الدروع والأسلحة الخفيفة. & 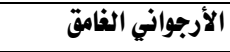 \\
\hline
\end{tabular}

جدول رقم (r) يوضح الألوان المستخدمة يِّ قاعات العرض بالمتحف ومدلولاتها.

ويجـب اختيـار ألـوان صـناديق العـرض بحيث تكـون مـرتبطلة بهـا يعـرض داخلها لأنها تعتبر

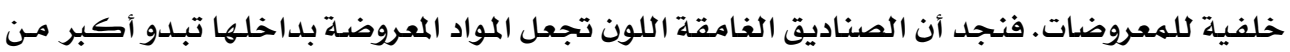

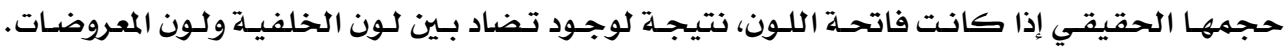

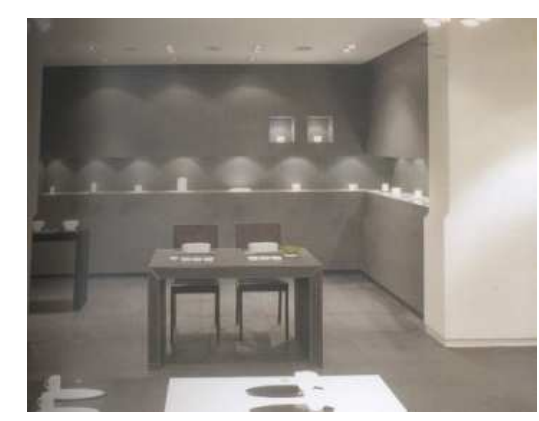
والعكس صحيح.

$$
\text { صورة (.r) توحيد لون الخلفية لإظهار المعروض }
$$

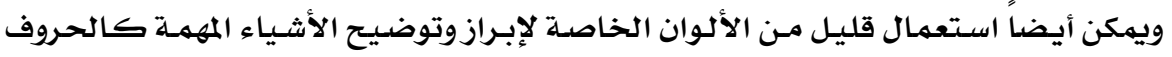

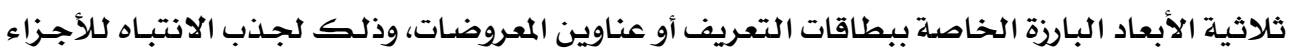

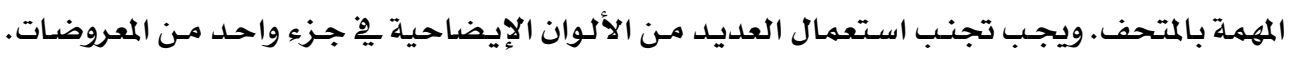

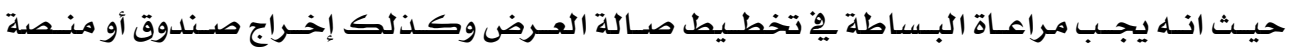

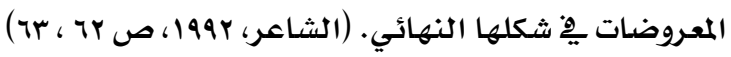

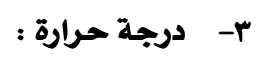

ويعرف بأنه السيطرة على درجات الحرارة والرطوبة، والتهوية والتصفية للتقليل من الملوثات

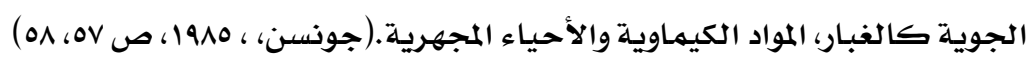


يمكن للتقلب أو التطرف يْ درجـات الحـرارة أن يسببـا الضرر بطرق عديدة ومختلفـة. حيث فيث

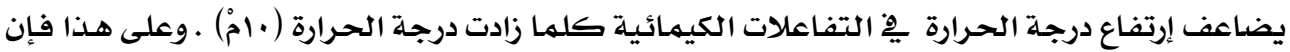

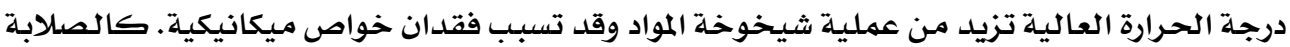

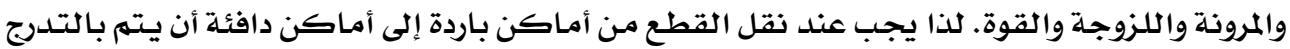

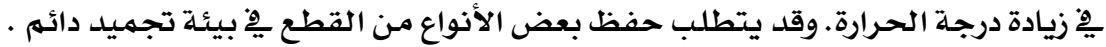

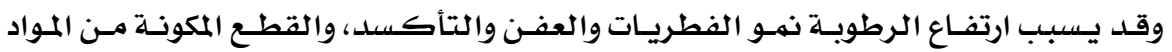

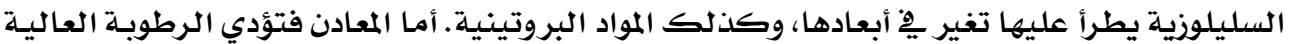
إلى تنشيط وجود ثاني أكسيد الكريون، وثاني أكسيد الكبريت والكلور، والحـوامض التي تنطلق مـن | الخشب.... وغيرها

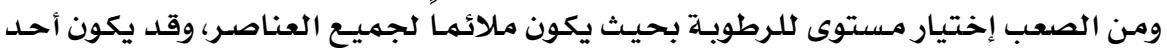

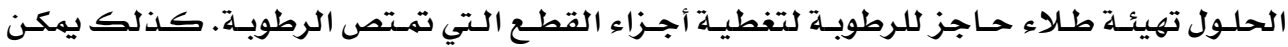

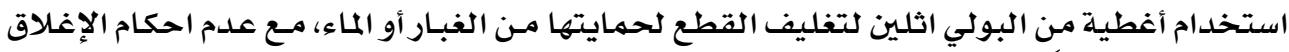

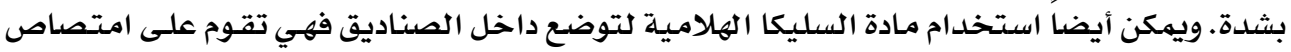

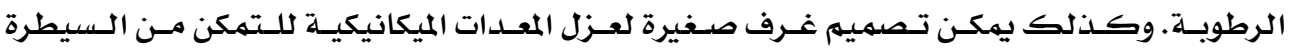
على الرطوبة.

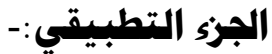

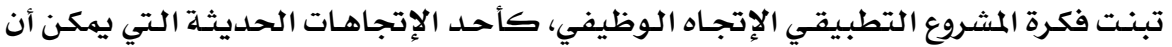

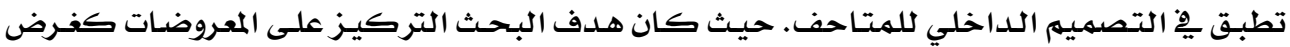

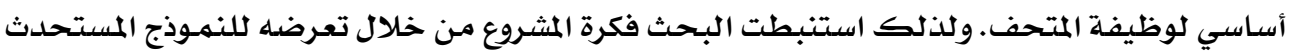

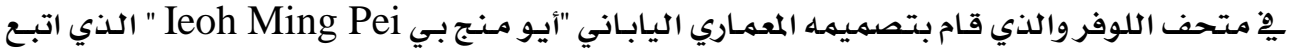
يف تصميمسه الإتجاه الوظيفي.

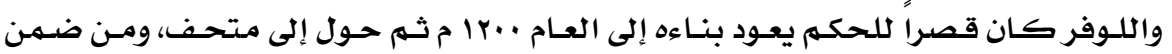

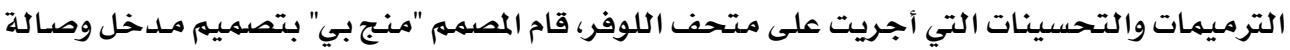

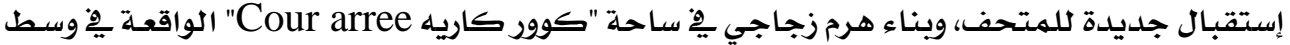

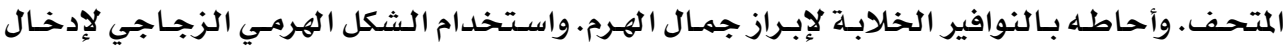

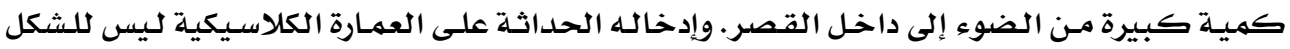

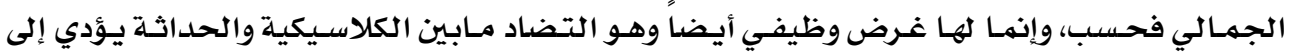

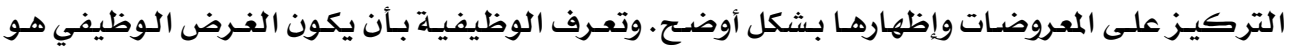

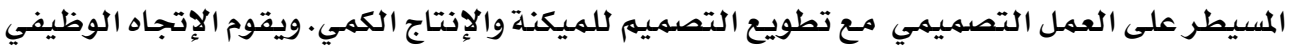

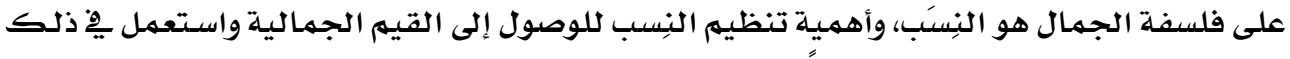

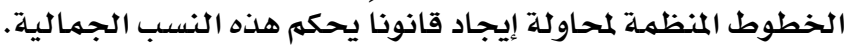


وقد وقع اختيار البحث على متحف "عبدالرؤوف حسن خليل" بمدينة جده، قاعة النحاسيات

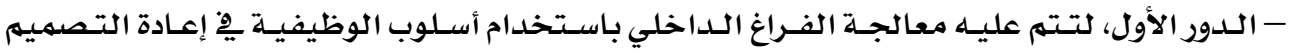

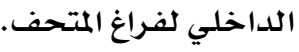

جدول (r) يوضح أهم السلبيات ِي المتحف والمعالجة المقترحة من البحث:-

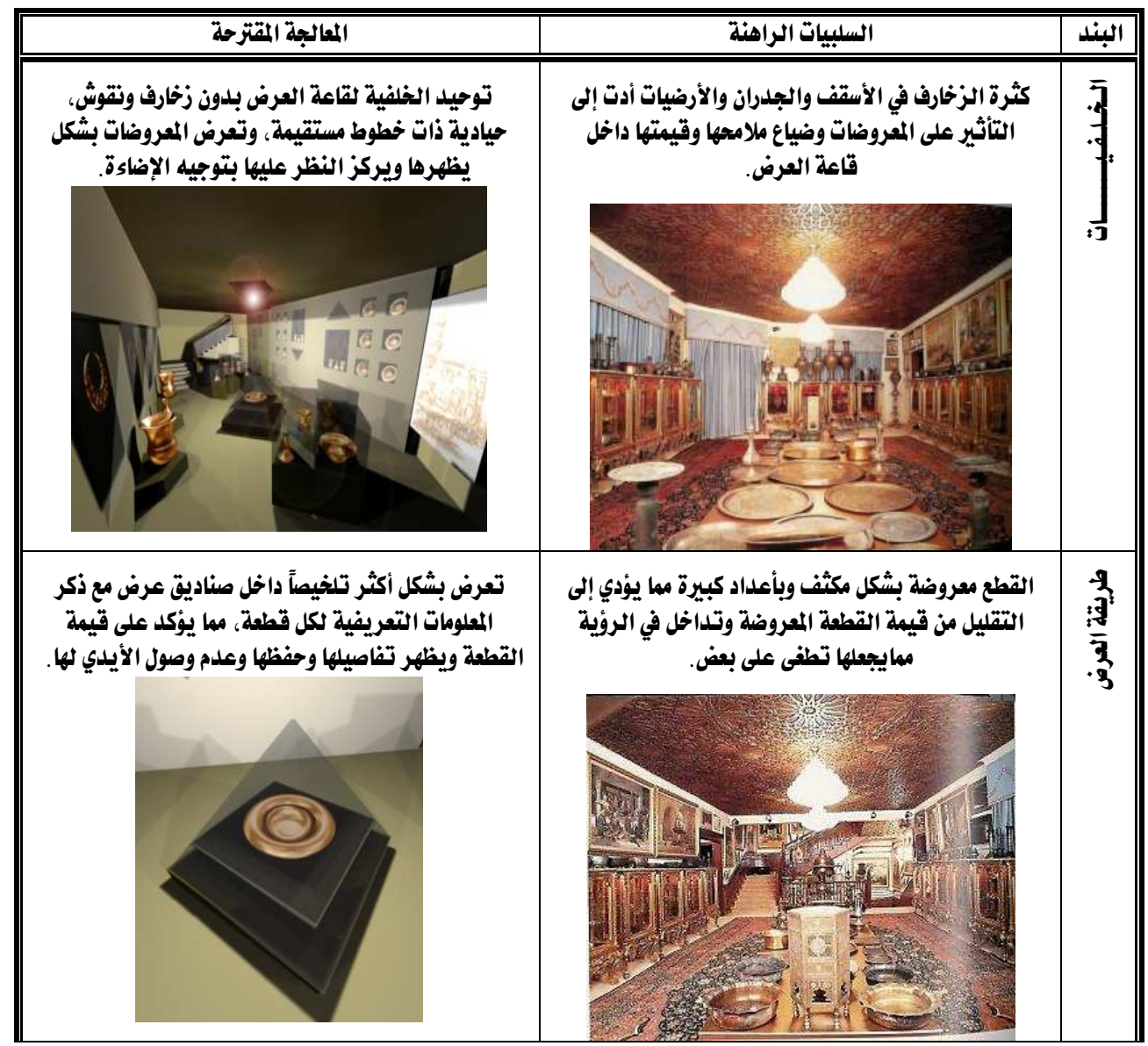




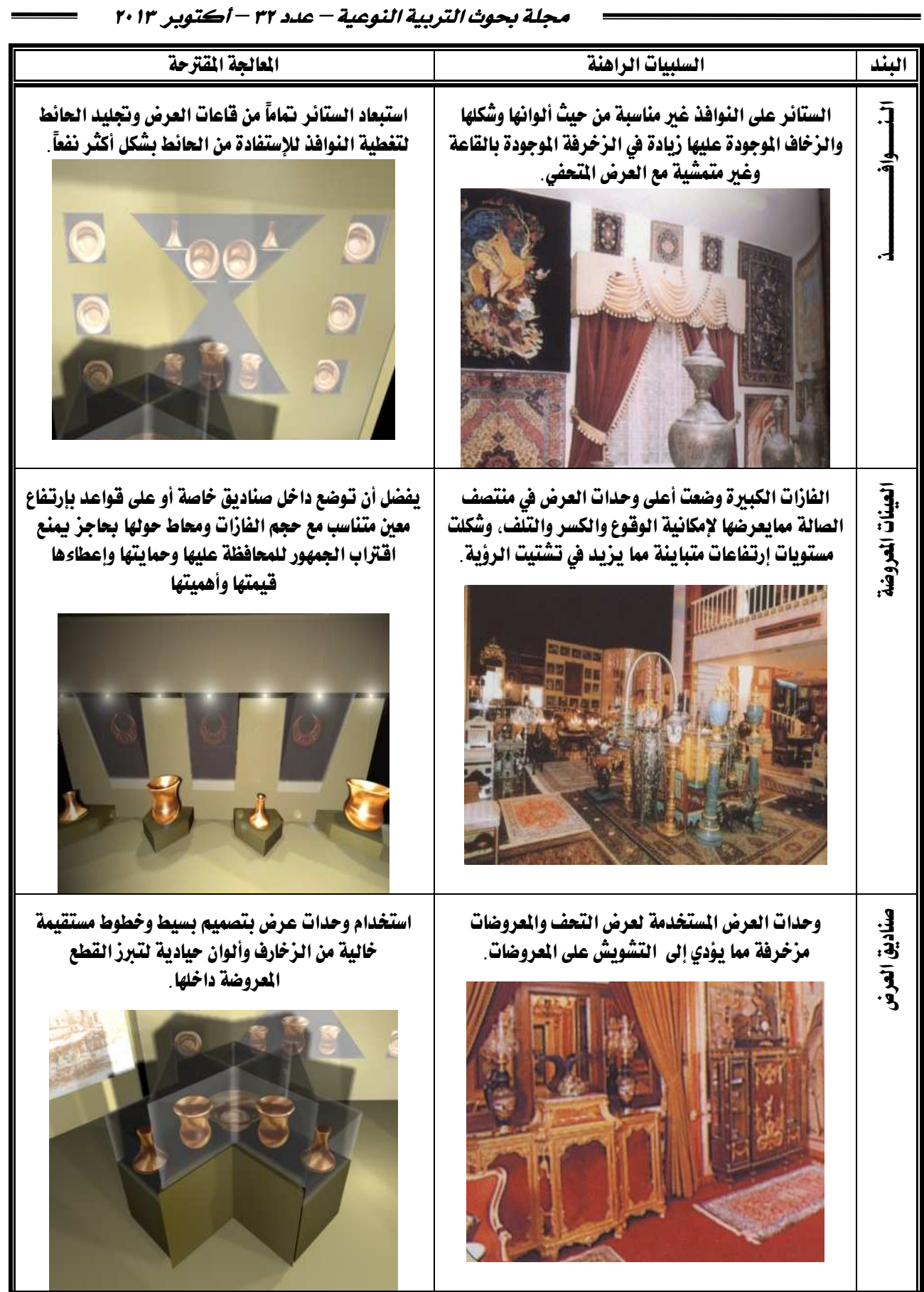




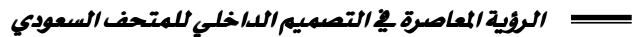

\begin{tabular}{|c|c|c|}
\hline المعالجة المقترحة & السلبيات الراهنة & البند \\
\hline 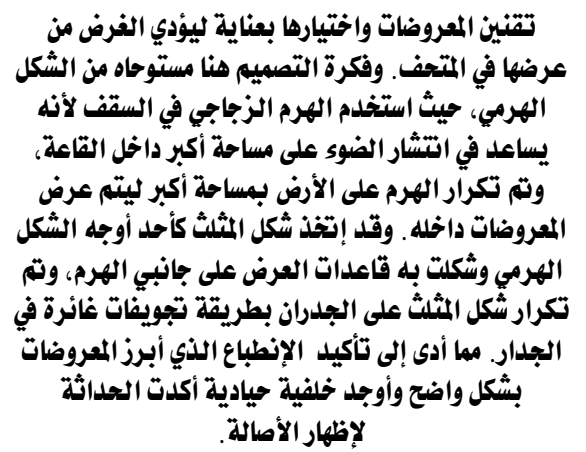 & 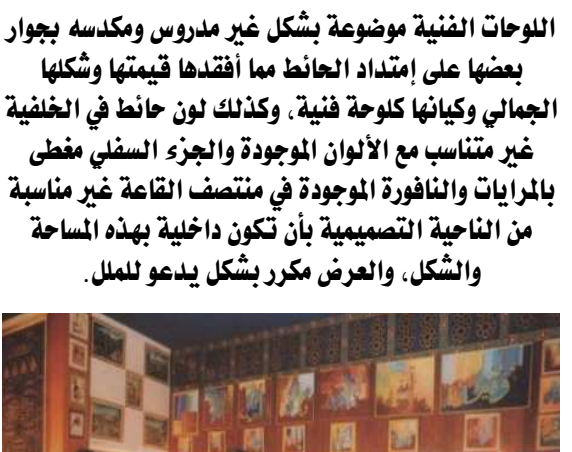 & 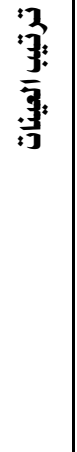 \\
\hline
\end{tabular}

أهم النتائج: -

l - توزيع المعروضات داخل صناديق خاصدة للعرض لحمايتها والتأكيد على قيمتها.

r- ت تقنين عدد القطع المعروضدة وإختيارها بعناية حتى لاتؤدي إلى ملل الزوار.

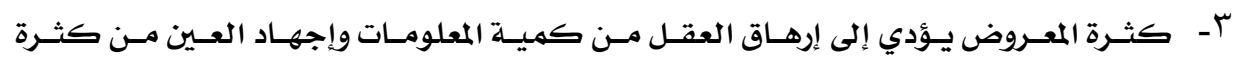

التركيز.

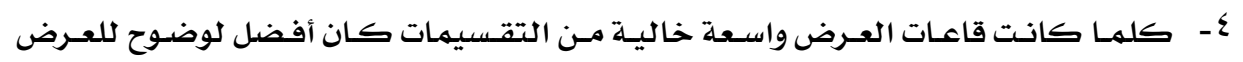

$$
\text { وإنسيابية الحركة. }
$$

قابُمهة المراجع:-

المراجع العربية:

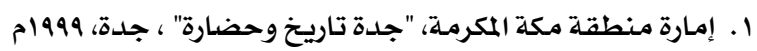

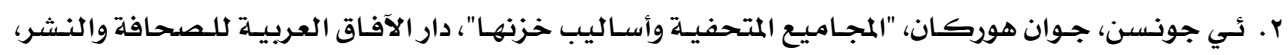

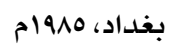

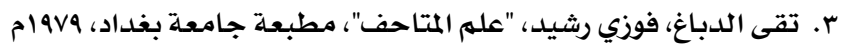

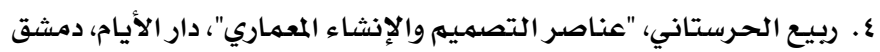




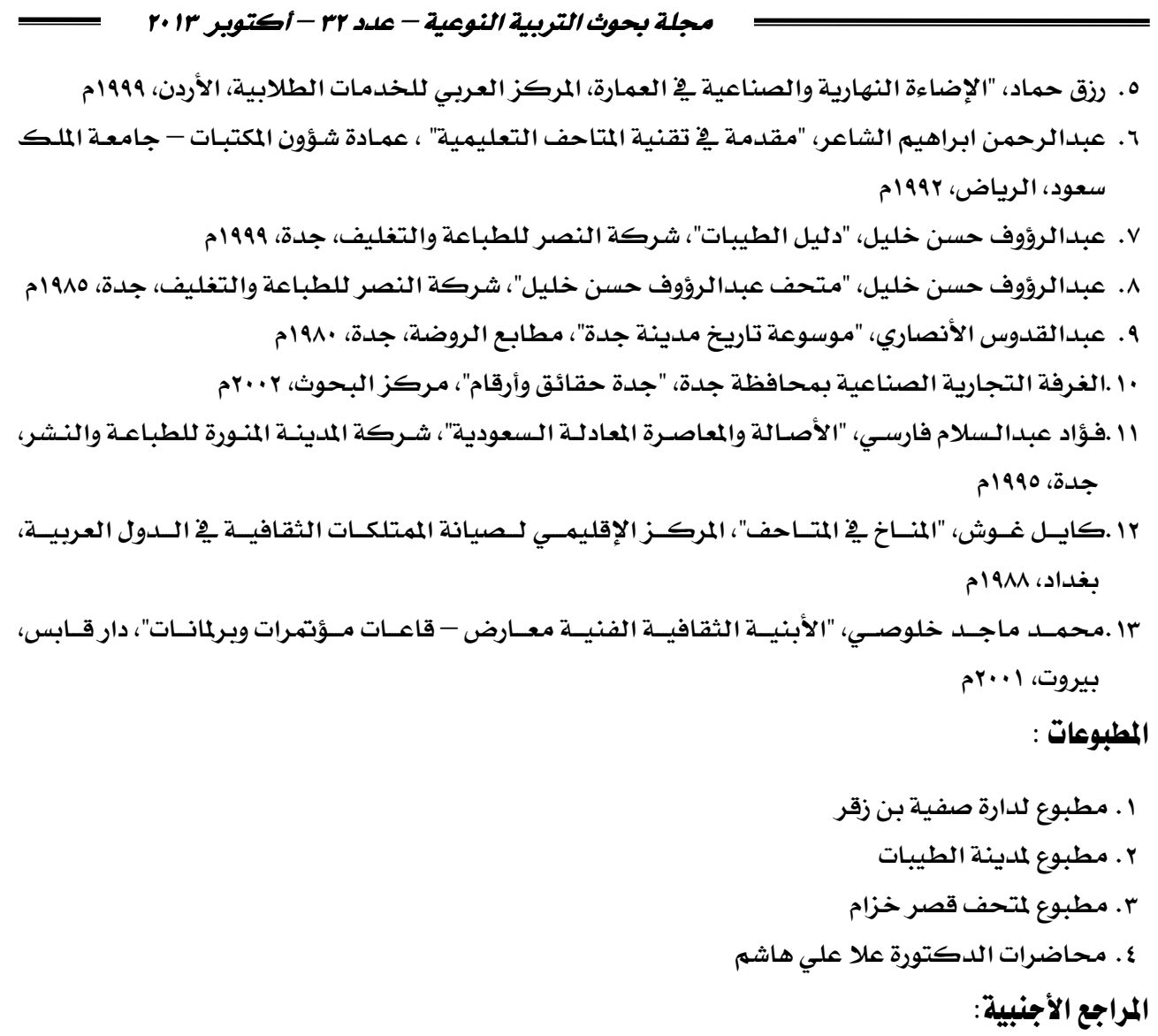

1.Andrea Gleiniger, Gerhard Matzig, "Paris Contemporary Architecture", New York, 1997

2.Bruce Pfeiffer, "Frank Lloyd Wright", Benedikt Taschen, Germany, 1994

3.George Mansell, "Anatomy of Architecture", the hamlyn publishing group, 1979

4. Hani M. Farsi, "Jeddah City of Art", Stacey International, London, 1991

5.Philip Jodidio, "Contemporary American Architecture", Benedikt Taschen, Italy, 1996

6."Interior World", exhibition, culture space, museum, No. 3

7."Interior World", exhibition space, museum, No. 16

1. http://www.Paris.org/museem/louver/plan

2. http://www.sfvisitor.org

3. http://members.tripod.com/ altshkeely/museums/louvre.html 